\section{Case Reports in Neurology}

Case Rep Neurol 2020;12:119-126

DOI: 10.1159/000505966

Published online: December 14, 2020

(c) 2020 The Author(s)

Published by S. Karger AG, Basel

www.karger.com/crn

This article is licensed under the Creative Commons Attribution-NonCommercial 4.0 International License (CC BY-NC) (http://www.karger.com/Services/OpenAccessLicense) Usage and distribution for commercial purposes requires written permission.

\title{
Transcranial Color-Coded Duplex Ultrasound for Assessing Cerebrovascular Reserve in Intracranial Dissection with Aneurysm
}

\author{
Narayanaswamy Venketasubramanian ${ }^{\mathrm{a}} \quad$ Andrew Eik Hock Tan ${ }^{\mathrm{b}}$ \\ Wee Thong $\mathrm{Neo}^{c}$ Manish Taneja ${ }^{\mathrm{a}}$ \\ aRaffles Neuroscience Centre, Raffles Hospital, Singapore, Singapore; buclear Medicine, \\ Raffles Hospital, Singapore, Singapore; 'Diagnostic Imaging, Raffles Hospital, \\ Singapore, Singapore
}

\section{Keywords}

Transcranial color-coded duplex ultrasound - Cerebrovascular reserve · Intracranial dissection - Dissecting aneurysm - Single-photon emission computed tomography . Transcranial color-coded sonography · Transcranial sonography · Transcranial imaging

\section{Abstract}

Intracranial artery dissection (IAD) is an uncommon cause of cerebral ischemia. It may lead to symptoms due to rupture of subadventitial aneurysms or thromboembolism from subintimal disruption. Severe stenosis may lead to reduced cerebrovascular reserve (CVR). While there are many methods of assessing CVR, we report a case of IAD with hemodynamic complications diagnosed by transcranial color-coded duplex (TCCD) ultrasonography. Our patient is a 38year-old female who presented with a 2-month history of nausea, then feeling faint whenever she got up suddenly. On the day of admission, she had gotten up to walk, felt nauseous, and the left upper limb felt "funny," after which she lost consciousness. Clinical and neurological

\begin{tabular}{ll}
\hline & N. Venketasubramanian \\
Raffles Neuroscience Centre, Raffles Hospital & \\
& 585 North Bridge Road, \#09-00 Raffles Specialist Centre \\
Singapore 188770 (Singapore) \\
drnvramani@gmail.com
\end{tabular}




\section{Case Reports in Neurology} \begin{tabular}{l|l} 
Case Rep Neurol 2020;12:119-126 \\
\hline DOI: 10.1159/000505966 & $\begin{array}{l}\text { @ 2020 The Author(s). Published by S. Karger AG, Basel } \\
\text { www.karger.com/crn }\end{array}$
\end{tabular}

Venketasubramanian et al.: Transcranial Color-Coded Duplex Ultrasound for Assessing Cerebrovascular Reserve in Intracranial Dissection with Aneurysm

examination was normal. Brain magnetic resonance (MR) imaging was normal. MR angiogram and subsequent computed tomography $(\mathrm{CT})$ angiogram showed flow attenuation in the M1 segment of the right middle cerebral artery (RMCA), with a possible flap. Catheter angiography was suggestive of a dissection with $2.7 \mathrm{~mm}$ pseudoaneurysm. TCCD showed very high velocities in the RMCA. The Breath-Holding Index (BHI) was 0.56 , suggestive of reduced CVR in the RMCA territory. Acetazolamide-enhanced single-photon emission CT showed reduced right frontal CVR. She was given clopidogrel for secondary prevention, and has remained well. BHI as measured by TCCD is a new method for assessing CVR in patients with cerebral ischemia.

(C) 2020 The Author(s)

Published by S. Karger AG, Basel

\section{Introduction}

Intracranial artery dissection (IAD) is an uncommon and often overlooked cause of stroke, especially in young adults [1]. Subintimal dissection leads to luminal stenosis (and hemodynamic compromise), or thromboembolism and subsequent cerebral ischemia; subadventitial dissection could lead to the formation of a pseudo-aneurysm and compression of surrounding structures [2]. Hemodynamic failure due to stenosis and inadequate compensatory collateral flow can lead to limb-shaking attacks [3]. Impaired cerebrovascular reserve (CVR) carries an almost 4-fold odds of stroke among those with significant carotid occlusive disease [4]. There are many modalities for the assessment of CVR - positron emission tomography, single-photon emission computed tomography (SPECT), perfusion and nuclear CT, perfusion magnetic resonance imaging (MRI), and transcranial Doppler (TCD); vasodilator challenges include carbon dioxide and acetazolamide [4]. TCD is an established technique for assessing cerebral vasomotor reactivity and autoregulation [5]. Increasing the carbon dioxide levels in the body by breath-holding provides a convenient and well-tolerated way of assessing carbon dioxide reactivity without requiring the administration of carbon dioxide [6]. A Breath-Holding Index (BHI) of $<0.69$ as measured by TCD raises the stroke risk by more than 3 fold [7]. Transcranial color-coded duplex (TCCD) ultrasound, also known as transcranial color-coded sonography, transcranial sonography, and transcranial imaging, which combines TCD with Bmode imaging and color-coding of Doppler flow, resembles TCD in probe frequency, acoustic windows employed, and velocity indices and criteria for normal and disease [8]. However, it differs from TCD in that B-mode imaging is first used to image the butterfly-shaped midbrain, then color-coded Doppler is employed to accurately visualize, locate, and identify the arteries of the Circle of Willis, before interrogating them with Doppler to determine flow characteristics - this removes vessel identification errors inherent in "blind" TCD. While TCCD has been used in the assessment of CVR capacity in healthy controls [9] and cognitive impairment [10], it has not yet been reported for cerebrovascular disease. We report a case of assessing CVR with BHI as measured by TCCD in a patient with IAD, with corroboration from acetazolamideenhanced SPECT.

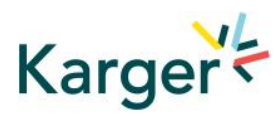




\section{Case Reports in Neurology}

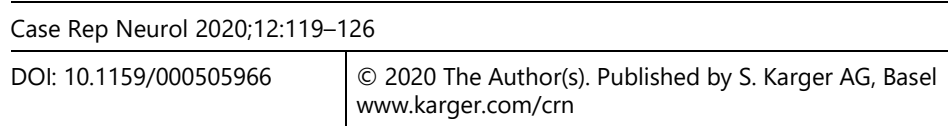

Venketasubramanian et al.: Transcranial Color-Coded Duplex Ultrasound for Assessing Cerebrovascular Reserve in Intracranial Dissection with Aneurysm

\section{Case Presentation}

Our patient is a 38-year-old female, right-handed, who presented with a 2-month history of nausea, then feeling faint whenever she got up suddenly, occasionally with palpitations. On the day of admission, she had gotten up to walk, felt nauseous, the left upper limb felt "funny," then she lost consciousness for a few seconds, during which she was seen to have upward rolling of the eyes, stiff limbs, and was cold and sweaty. No incontinence or tongue bites occurred, and she was well postictally. She had a history of asthma, but no hypertension, diabetes mellitus, hyperlipidemia, or smoking. She was not on medication, but her father had had seizures.

Clinically, she was well, fully alert and orientated. She was not pale. Blood pressure was equal in both upper limbs and normal, pulse rate and rhythm were normal. There was no postural hypotension, and cardiac examination was normal. No ocular or cervical bruit was present, and neither were aphasia, anopia, and neglect. No neurocutaneous were stigmata found, the pupils were equal in size and reactive, and fundoscopy was normal. She had full eye, face, palate, tongue, neck movements. Limb tone, power, reflexes, and coordination were normal, as were pain sensation and gait.

MRI of the brain was normal. MR angiogram and subsequent CT angiogram showed flow attenuation in the M1 segment of the right middle cerebral artery (RMCA), with a possible flap (Fig 1). Catheter angiography was suggestive of a dissection with $2.7 \mathrm{~mm}$ pseudoaneurysm (Fig. 1).

TCCD showed very high velocities in the RMCA. BHI was 0.56 , suggestive of reduced CVR in the RMCA territory (Fig. 2, Table 1). SPECT showed reduced right frontal CVR (Fig. 3).

Full blood count, glucose, renal, and liver panels were normal. LDL-cholesterol was 106 $\mathrm{mg} / \mathrm{dL}$. Fasting homocysteine was normal. Electroencephalogram was normal. Electrocardiogram and transthoracic echocardiography were normal. Twenty-four-hour Holter monitoring showed occasional ectopic beats. The tilt table test was positive.

The patient was commenced on clopidogrel and advised to get up slowly whenever she needed to. She is still on follow-up 4 months after the onset of symptoms.

\section{Discussion}

In this case report, we were able to demonstrate reduced CVR by TCCD in a patient with symptoms suggestive of hemodynamic cerebrovascular ischemia, imaging evidence of significant intracranial stenosis, and supported by another established CVR technique (acetazolamide-enhanced SPECT).

Our patient presented with symptoms of cerebral ischemia after sudden posture change - her global cerebral hemodynamic failure was supported by her positive tilt table test where she quickly lost consciousness very soon after being moved to the upright position. The occurrence of left upper-limb weakness just before she lost consciousness was suggestive of 


\section{Case Reports in Neurology} \begin{tabular}{l|l} 
Case Rep Neurol 2020;12:119-126 \\
\hline DOI: 10.1159/000505966 & $\begin{array}{l}\text { @ } 2020 \text { The Author(s). Published by S. Karger AG, Basel } \\
\text { www.karger.com/crn }\end{array}$
\end{tabular}

Venketasubramanian et al.: Transcranial Color-Coded Duplex Ultrasound for Assessing Cerebrovascular Reserve in Intracranial Dissection with Aneurysm

an additional mechanism of severe stenosis of arteries supplying her right hemisphere. This was subsequently found to be due to RMCA stenosis owing to dissection.

Further evidence of reduced right hemispheric CVR was found in her reduced BHI on TCCD. In this modality, the velocity of blood flow in a large intracranial artery, usually the MCA, is measured before and after a period of breath-holding, usually for $30 \mathrm{~s}$. BHI is calculated by dividing the percentage increase in the mean flow velocity (MFV) occurring due to breath-holding, by the length of time (s) that subjects hold their breath after a normal inspiration ([MFV at the end of breath-holding minus rest MFV / rest MFV] $\times 100$ / s of breathholding). A value of $<0.69$ indicates reduced CVR and increased stroke risk [8]. Our patient had a BHI of 0.56 .

There are some technical challenges with performing CVR using TCCD. The hand-held probe for TCCD is bigger in size and bulkier than the probe used for TCD. It can be tiring holding such a probe steadily throughout the procedure. Minute unintentional head movements could have an impact on the stable position of a hand-held probe. There is no commercially available head frame for the TCCD probe; such frames are widely available for the TCD probes and allow continuous monitoring throughout the test and the probes stay in a stable position despite head movements. Possible solutions include supporting the hand holding the probe as much as possible, e.g. with pillows or small sand bags; thus, the study can be performed without a break; the patient is also asked to stay as still as possible. Another approach is to perform the insonations only at the start and end of breath-holding for just a few seconds or at least until the waveforms are stable. This, however, requires the presence of a neurosonologist to again locate the intracranial artery, which can take a little time and the effect of breath-holding may be missed; the probe may be unwittingly placed at a slightly different location, which may have an impact on the amplitude of velocities recorded. For the patient described herein, the first approach was successfully used after a thorough explanation to the patient who was very compliant. Another issue is that the left- and right-side TCCD insonations were done consecutively and not simultaneously (as is occurs with TCD using a head frame). Machine software does not routinely allow 2 probes to be in operation simultaneously; TCCD headframes are not available unlike TCD where the 2 probes can be mounted on a frame and operate simultaneously. It will be difficult to obtain 2 TCCD machines and to operate them simultaneously -2 neurosonologists will thus be needed, one to insonate each side. Thus, 2 studies are needed, one on each side; the studies need to be performed consecutively after a short break to allow return to baseline, and the patient needs to be able to hold the breath fully during both studies - this is what was done in our patient.

The patient's reduced BHI was corroborated by acetazolamide-enhanced SPECT, where the relative blood flow of the hemispheres is assessed using HMPAO and is compared before and after the intravenous administration of acetazolamide, a carbonic anhydrase inhibitor that raises the level of carbon dioxide in the blood. There is a strong correlation between CVR assessment by TCD and acetazolamide-enhanced SPECT [11].

As mentioned above, a reduced CVR is not a benign condition as it carries a high stroke risk $[4,7]$. Among those with symptomatic, significant MCA stenosis, reduced CVR carries an annual risk of stroke of $14 \%$ [12]. Thus, our patient is at significant risk of stroke ipsilateral to her MCA stenosis. 


\section{Case Reports in Neurology}

The most appropriate management of IAD is still unclear [1]; there are no randomised controlled trials to inform on the best approach. Even in the setting of extracranial cervical artery dissection, there is no clear evidence of the superiority of anticoagulation over antiplatelet therapy in reducing the risk of recurrent cerebral ischemia [13]. We thus decided to treat her with antiplatelets - as she had asthma, clopidogrel was given.

It is also unclear what the best treatment for intracranial dissecting aneurysms is. While those with hemorrhage may best be treated surgically, by clipping or wrapping of the aneurysm, the treatment for those with ischemia is unknown [14]. Overall, for intracranial stenosis, stenting has a higher complication rate than best medical therapy for atherosclerotic disease; the role of indirect surgical revascularization is unknown [15].

\section{Conclusion}

CVR has important prognostic value for patients with cerebral ischemia. While there are a number of modalities for assessing CVR, the BHI as determined by TCD is a simple, inexpensive, safe, and valuable parameter of CVR. We have shown in this case report that TCCD may also be used to assess CVR.

\section{Statement of Ethics}

This research complies with the guidelines for human studies and was conducted ethically in accordance with the World Medical Association Declaration of Helsinki. The patient gave informed consent to publish the case.

\section{Conflict of Interest Statement}

The authors have no conflicts of interest to declare.

\section{Funding Sources}

There are no funding sources to disclose

\section{Author Contributions}

Narayanaswamy Venketasubramanian - conceived the project, was the principle clinician managing the patient, performed the ultrasound study, and wrote the manuscript. Andrew Eik Hock Tan - nuclear radiologist managing the patient, performed and interpreted the SPECT study, and reviewed the manuscript. Wee Thong Neo - diagnostic radiologist managing the 


\section{Case Reports in Neurology}

Case Rep Neurol 2020;12:119-126

Venketasubramanian et al.: Transcranial Color-Coded Duplex Ultrasound for Assessing Cerebrovascular Reserve in Intracranial Dissection with Aneurysm

patient, performed and interpreted the MRI and CT scans, and reviewed the manuscript. Manish Taneja - interventional radiologist managing the patient, performed and interpreted the cerebral angiogram, and reviewed the manuscript.

\section{References}

1 Debette S, Compter A, Labeyrie MA, Uyttenboogaart M, Metso TM, Majersik JJ, et al. Epidemiology, pathophysiology, diagnosis, and management of intracranial artery dissection. Lancet Neurol. 2015 Jun;14(6):640-54.

2 Sikkema T, Uyttenboogaart M, Eshghi O, De Keyser J, Brouns R, van Dijk JM, et al. Intracranial artery dissection. Eur J Neurol. 2014 Jun;21(6):820-6.

3 Liu YC, Chung CP, Yip PK, Wang V. Spontaneous middle cerebral arterial dissection presented with limb shaking. Acta Neurol Taiwan. 2009 Mar;18(1):26-9.

4 Gupta A, Chazen JL, Hartman M, Delgado D, Anumula N, Shao H, et al. Cerebrovascular reserve and stroke risk in patients with carotid stenosis or occlusion: a systematic review and meta-analysis. Stroke. 2012 Nov;43(11):2884-91.

5 Edmonds HL Jr, Isley MR, Sloan TB, Alexandrov AV, Razumovsky AY. American Society of Neurophysiologic Monitoring and American Society of Neuroimaging joint guidelines for transcranial doppler ultrasonic monitoring. J Neuroimaging. 2011 Apr;21(2):177-83.

6 Markus HS, Harrison MJ. Estimation of cerebrovascular reactivity using transcranial Doppler, including the use of breath-holding as the vasodilatory stimulus. Stroke. 1992 May;23(5):668-73.

7 Silvestrini M, Vernieri F, Pasqualetti P, Matteis M, Passarelli F, Troisi E, et al. Impaired cerebral vasoreactivity and risk of stroke in patients with asymptomatic carotid artery stenosis. JAMA. 2000 Apr;283(16):2122-7.

8 Krejza J, Baumgartner RW. Clinical applications of transcranial color-coded duplex sonography. J Neuroimaging. 2004 Jul;14(3):215-25.

9 Giorli E, Tognazzi S, Briscese L, Bocci T, Mazzatenta A, Priori A, et al. Transcranial Direct Current Stimulation and Cerebral Vasomotor Reserve: A Study in Healthy Subjects. J Neuroimaging. 2015 Jul-Aug;25(4):571-4.

10 Urbanova BS, Schwabova JP, Magerova H, Jansky P, Markova H, Vyhnalek M, et al. Reduced Cerebrovascular Reserve Capacity as a Biomarker of Microangiopathy in Alzheimer's Disease and Mild Cognitive Impairment. J Alzheimers Dis. 2018;63(2):465-77.

11 Engelhardt M, Pfadenhauer K, Zentner J, Grimmer S, Wachenfeld-Wahl C, Heidenreich P, et al. [Impaired cerebral autoregulation in asymptomatic patients with carotid artery stenosis: comparison of acetazolamide-SPECT and transcranial CO(2)-dopplersonography]. Zentralbl Chir. 2004 Jun;129(3):178-82.

12 Zhang W, Yin Y, Zhang Y, Yang F, Shi W, Chen D, et al. Influence of cerebrovascular reactivity on outcome of the patients with $\geq 50 \%$ symptomatic unilateral middle cerebral artery stenosis. Int J Neurosci. 2018 Jan;128(1):42-7.

13 Kennedy F, Lanfranconi S, Hicks C, Reid J, Gompertz P, Price C, et al.; CADISS Investigators. Antiplatelets vs anticoagulation for dissection: CADISS nonrandomized arm and meta-analysis. Neurology. 2012 Aug;79(7):686-9.

14 Chuang MJ, Lu CH, Cheng MH. Management of middle cerebral artery dissecting aneurysm. Asian J Surg. 2012 Jan;35(1):42-8.

15 Gonzalez NR, Liebeskind DS, Dusick JR, Mayor F, Saver J. Intracranial arterial stenoses: current viewpoints, novel approaches, and surgical perspectives. Neurosurg Rev. 2013 Apr;36(2):175-84. 


\section{Case Reports in Neurology}
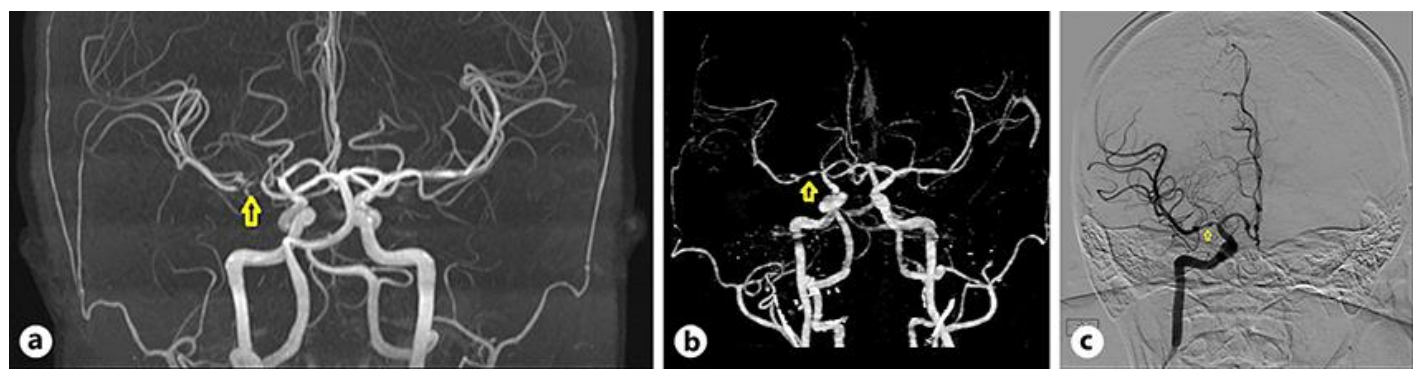

Fig. 1. Intracranial dissection as seen by MR angiogram(a), CT angiogram (b), and digital subtraction angi$\operatorname{ogram}(c)$.
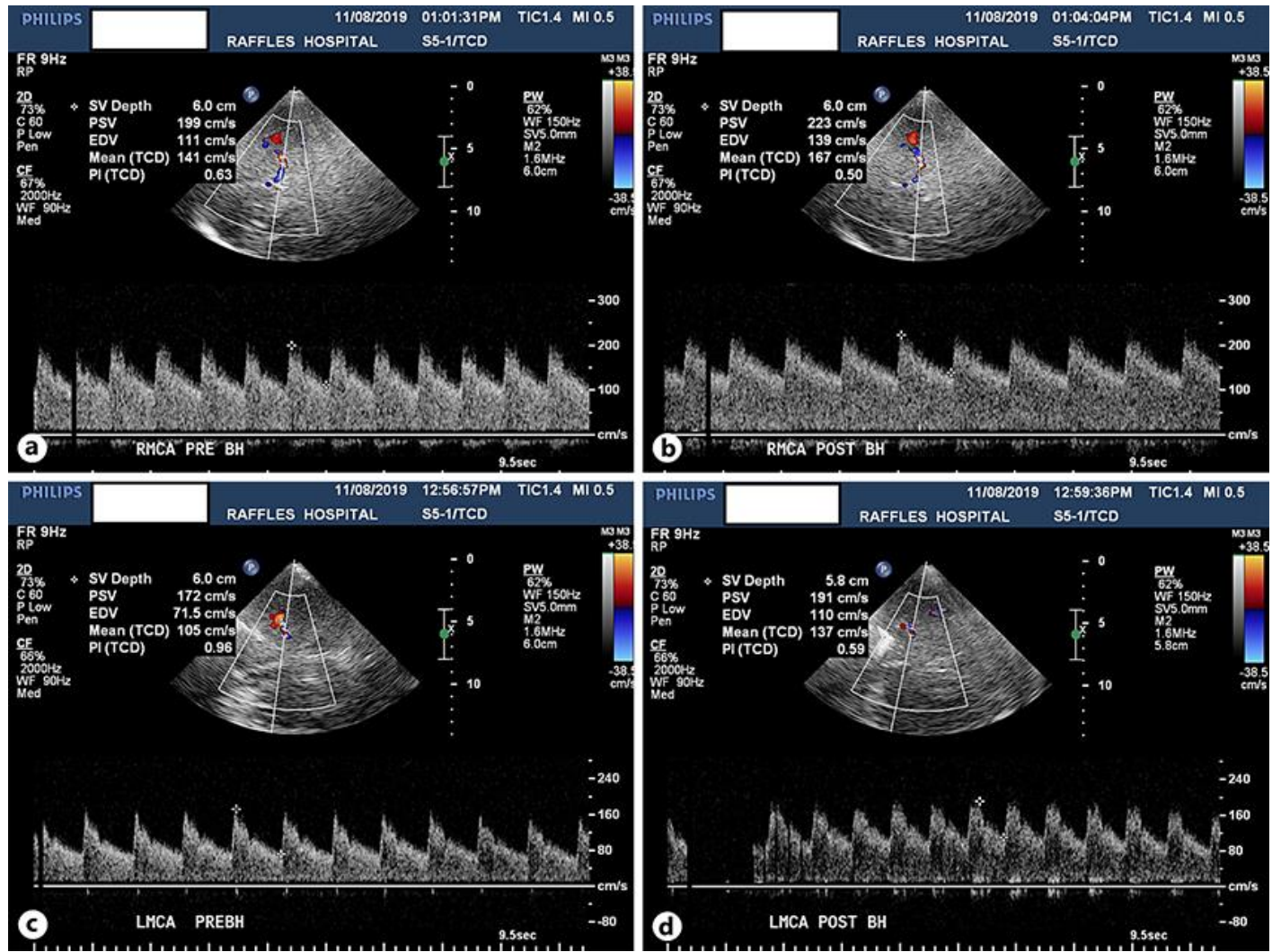

Fig. 2. Transcranial color-coded Doppler ultrasonography of the middle cerebral arteries showing high velocities at baseline (a) and only slight increase after breath-holding (b) in the RMCA. This compares with normal velocities at baseline (c) and increase after breath-holding (d) in the left middle cerebral artery (LMCA). 


\section{Case Reports in Neurology}

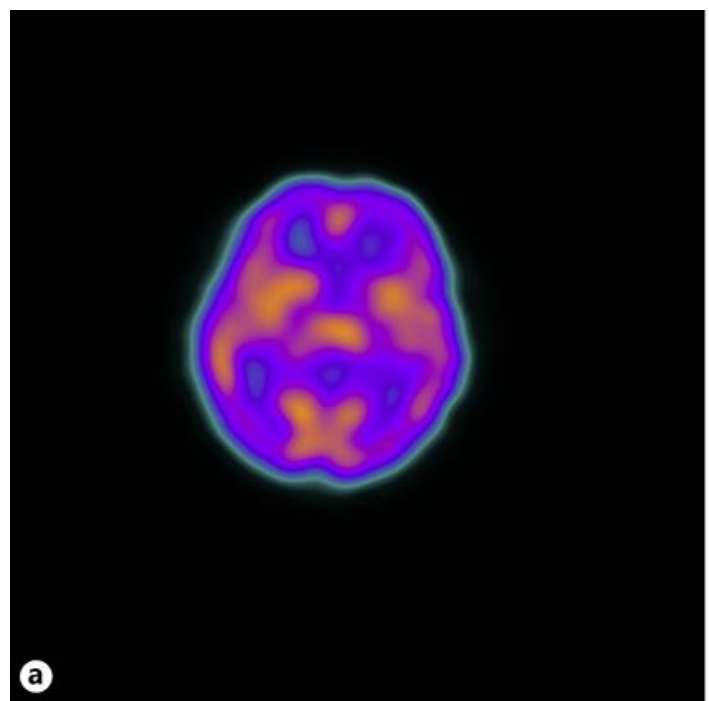

Case Rep Neurol 2020;12:119-126

DOI: $10.1159 / 000505966$

(C) 2020 The Author(s). Published by S. Karger AG, Basel www.karger.com/crn

Venketasubramanian et al.: Transcranial Color-Coded Duplex Ultrasound for Assessing Cerebrovascular Reserve in Intracranial Dissection with Aneurysm

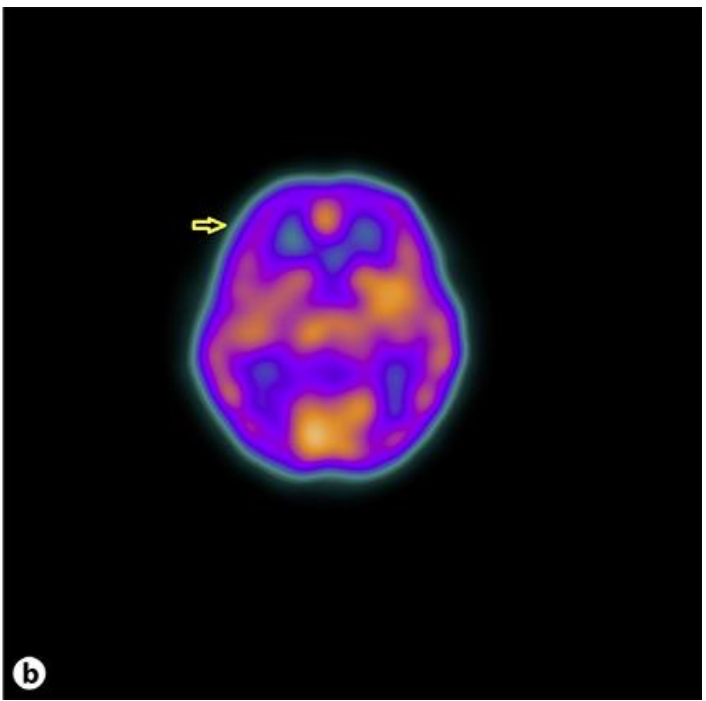

Fig. 3. Single-photon emission tomography before (a) and after (b) acetazolamide, showing a reduced blood flow in the right frontal region.

Table 1. Transcranial color-coded duplex findings before and after breath-holding

\begin{tabular}{|c|c|c|c|c|c|c|c|c|c|c|}
\hline \multirow[t]{2}{*}{ Artery } & \multicolumn{5}{|l|}{ Right } & \multicolumn{5}{|l|}{ Left } \\
\hline & $\begin{array}{l}\text { Depth, } \\
\mathrm{mm}\end{array}$ & $\begin{array}{l}\mathrm{PSV}, \\
\mathrm{cm} / \mathrm{s}\end{array}$ & $\begin{array}{l}\mathrm{EDV}, \\
\mathrm{cm} / \mathrm{s}\end{array}$ & $\begin{array}{l}\mathrm{MV}, \\
\mathrm{cm} / \mathrm{s}\end{array}$ & PI & $\begin{array}{l}\text { Depth, } \\
\mathrm{mm}\end{array}$ & $\begin{array}{l}\mathrm{PSV}, \\
\mathrm{cm} / \mathrm{s}\end{array}$ & $\begin{array}{l}\mathrm{EDV}, \\
\mathrm{cm} / \mathrm{s}\end{array}$ & $\begin{array}{l}\mathrm{MV}, \\
\mathrm{cm} / \mathrm{s}\end{array}$ & PI \\
\hline \multirow[t]{4}{*}{ MCA } & 45 & 144 & 87 & 93 & 0.83 & & & & & \\
\hline & 50 & 155 & 72 & 99 & 0.82 & 50 & 110 & 48 & 68 & 0.91 \\
\hline & 55 & 248 & 143 & 178 & 0.59 & 55 & 154 & 70 & 98 & 0.86 \\
\hline & 60 & 202 & 117 & 145 & 0.59 & 60 & 159 & 73 & 102 & 0.81 \\
\hline Before breath-holding & 60 & 199 & 111 & 141 & 0.63 & 60 & 172 & 72 & 105 & 0.96 \\
\hline After breath-bolding & 60 & 223 & 139 & 167 & 0.50 & 58 & 191 & 110 & 137 & 0.59 \\
\hline
\end{tabular}

BHI. RMCA $=(167-141) \times 100 /(141 \times 33)=0.56$. LMCA $=(137-105) \times 100 /(105 \times 39)=0.78$. PSV, peak systolic velocity; EDV, end-diastolic velocity; MV, mean velocity; PI, pulsatility index. 